\title{
GESTÃO PEDAGÓGICA NO BLOCO DE ALFABETIZAÇÃO A PARTIR DA IMPLANTAÇÃO DO ENSINO FUNDAMENTAL DE NOVE ANOS
}

http://dx.doi.org/10.5902/2318133840675

\author{
Jordana Rex Braun ${ }^{1}$ \\ Doris Pires Vargas Bolzan²
}

\begin{abstract}
Resumo
Neste texto são apresentados resultados de uma pesquisa realizada com as professoras do bloco pedagógico e a coordenadora pedagógica de uma escola de Santa Maria/RS. O objetivo foi compreender como ocorre a gestão pedagógica dos processos de escolarização no ciclo de alfabetização com a implantação do ensino fundamental de 9 anos. Destacamos que o trabalho do professor é perpassado por mudanças legais que influenciam na sua organização. Assim, ele requer uma atenção constantes às emergências sociais e culturais e às necessidades das crianças, visando a qualificar as práticas pedagógicas. A gestão pedagógica requer ir além da sala de aula, configurando-se em um espaço de trabalho colaborativo para qualificar o processo de alfabetização no bloco pedagógico.

Palavras-chave: educação básica; bloco pedagógico; gestão pedagógica.
\end{abstract}

\section{PEDAGOGICAL MANAGEMENT IN THE LITERACY BLOCK BY THE IMPLANTATION OF NINE-YEAR FUNDAMENTAL EDUCATION}

\section{Abstract}

This text presents the results of research conducted with the teachers of the pedagogical block and the pedagogical coordinator of a school in Santa Maria/RS. The objective was to understand how the pedagogical management of schooling processes in the Literacy Cycle occurs with the implementation of the 9-year Elementary School. We emphasize that the teacher's work is permeated by legal changes that influence his organization. Thus, it requires constant attention to social and cultural emergencies and children's needs in order to qualify pedagogical practices. Pedagogical management requires going beyond the classroom, setting up a collaborative workspace to qualify the literacy process in the pedagogical block.

Key-words: basic education; pedagogical block; pedagogical management.

\footnotetext{
1 Universidade Federal de Santa Maria, Brasil. E-mail: jordanabraun@hotmail.com.

2 Universidade Federal de Santa Maria, Brasil. E-mail: dbolzan19@gmail.com. 


\section{Introdução}

escola é um espaço de transformação. Ao longo dos anos esse espaço
social, cultural e histórico foi acompanhando as modificações da sociedade
globalizada, marcada pelas tecnologias da informação e do conhecimento. Com o passar dos tempos as instituições formais de ensino, ambientes pensados para o desenvolvimento do ensinar e do educar de jovens e crianças, adequou-se para atender as demandas das múltiplas infâncias que vieram constituir esse espaço.

Novas organizações surgiram a partir de demandas nos processos de ensinar e de aprender, principalmente da criança pequena, mais especificamente no ensino fundamental. Como exemplo podemos mencionar a recente implantação do bloco de alfabetização, que surgiu a partir do acréscimo de um ano no ensino fundamental, por meio da lei 11.274, de 6 de setembro de 2006.

Tudo isso demanda a restruturação curricular e muitas reflexões sobre o que se espera da criança que agora chega à escola com seis anos de idade e possui três anos para consolidar seu processo de alfabetização, respeitando a progressão continuada instituída por intermédio do bloco de alfabetização. Assim, o estudante tem a possibilidade de avançar gradativamente na leitura e na escrita, sendo que a retenção é somente permitida a partir do 3 o ano.

A partir disso surgiu a necessidade de conhecer como acontece esse processo no ensino municipal de Santa Maria/RS e como os saberes e os fazeres perpassam a gestão pedagógica em meio a alfabetização no ciclo inicial de leitura e de escrita.

\section{Metodologia}

Para isso foi realizado um levantamento de dados dos últimos censos escolares disponibilizados pelo Instituto Nacional de Estudos e Pesquisas Educacionais acerca das taxas de aprovação e de reprovação nos anos iniciais no ensino fundamental desde o ano de 2007, período seguinte ao início da implantação do ensino fundamental de nove anos. Por meio da análise e interpretação de índices dos últimos dez anos propusemo-nos a pensar o contexto de Santa Maria/RS. Dessa forma foi necessária uma consulta a diferentes sites que possibilitassem o acesso aos dados tanto na esfera macro, no âmbito de Brasil, regiões e estados, quanto na instância micro, restringindo o nosso foco a Santa Maria.

Utilizamos o site do Inep para ao alcance de índices nas maiores instâncias - nação, regiões e Estados. Por meio dele conseguimos analisar a evolução das taxas de aprovação e de reprovação nos anos iniciais entre os anos de 2007 e de 2016, além de consultar o total de alunos no ensino fundamental e, especificamente, nos anos iniciais. Tendo como enfoque o município de Santa Maria/RS, recorremos à Secretaria Municipal de Educação para o acesso aos dados das escolas municipais, tanto de zona rural, quanto urbana, no mesmo período de tempo.

Neste estudo utilizamos a pesquisa qualitativa narrativa sociocultural, pois "comporta uma análise que centra sua atenção nos processos de construção coletiva, a partir da realidade sociocultural dos sujeitos participantes do processo" (Bolzan, 2006, p. 386). As narrativas, nesse sentido, surgem como instrumento fundamental para dar voz a essas 
pessoas, "colocam a experiência em uma sequência, encontram possíveis explicações para isso, e jogam com a cadeia de acontecimentos que constroem a vida social e individual" (Bauer; Gaskell, 2002, p. 91). A partir delas, é possível enunciar elementos que constituem as pessoas como profissionais nos espaços escolares, de história e de cultura.

Com isso os sujeitos que narram suas vivências e experiências externalizam sentimentos e aprendem e constroem conhecimentos por meio de suas próprias falas e reflexões. Assim,

um dos aspectos mais importantes do uso da narrativa na investigação é o fato de enforcarmos a voz do sujeito que é narrado e a voz de quem o narra. Os relatos revelam múltiplas vozes entrelaçadas durante a narração, devendo explicitar sua estrutura através da descrição do cenário e da trama, localizados em um tempo e espaço. (Bolzan, 2002, p. 23)

As entrevistas narrativas, a partir de tópicos guias, foram realizadas com três professoras do bloco pedagógico de uma escola municipal de Santa Maria/RS, bem como com a coordenadora pedagógica. Após serem transcritas as mesmas foram devolvidas para que as participantes tivessem a oportunidade de lerem as narrativas, bem como alterarem algum tópico, caso julgassem necessário.

\section{Pressupostos e concepções: as professoras em foco}

Como mencionamos anteriormente, realizamos um levantamento de dados na Smed de Santa Maria/RS para buscar subsídios que sustentassem a nossa escolha pela temática e justificassem a necessidade de se pensar a gestão pedagógica no bloco de alfabetização. Com isso apresentamos alguns dados nos gráficos em sequência, enfocando a aprovação e a reprovação nos anos iniciais do Ensino Fundamental, no município em pesquisa, desde o ano de 2007 até o ano de 2016.

\section{Gráfico 1 -}

Evolução da taxa de aprovação nos anos iniciais do ensino fundamental em Santa Maria/RS, no período de 2007 a 2016

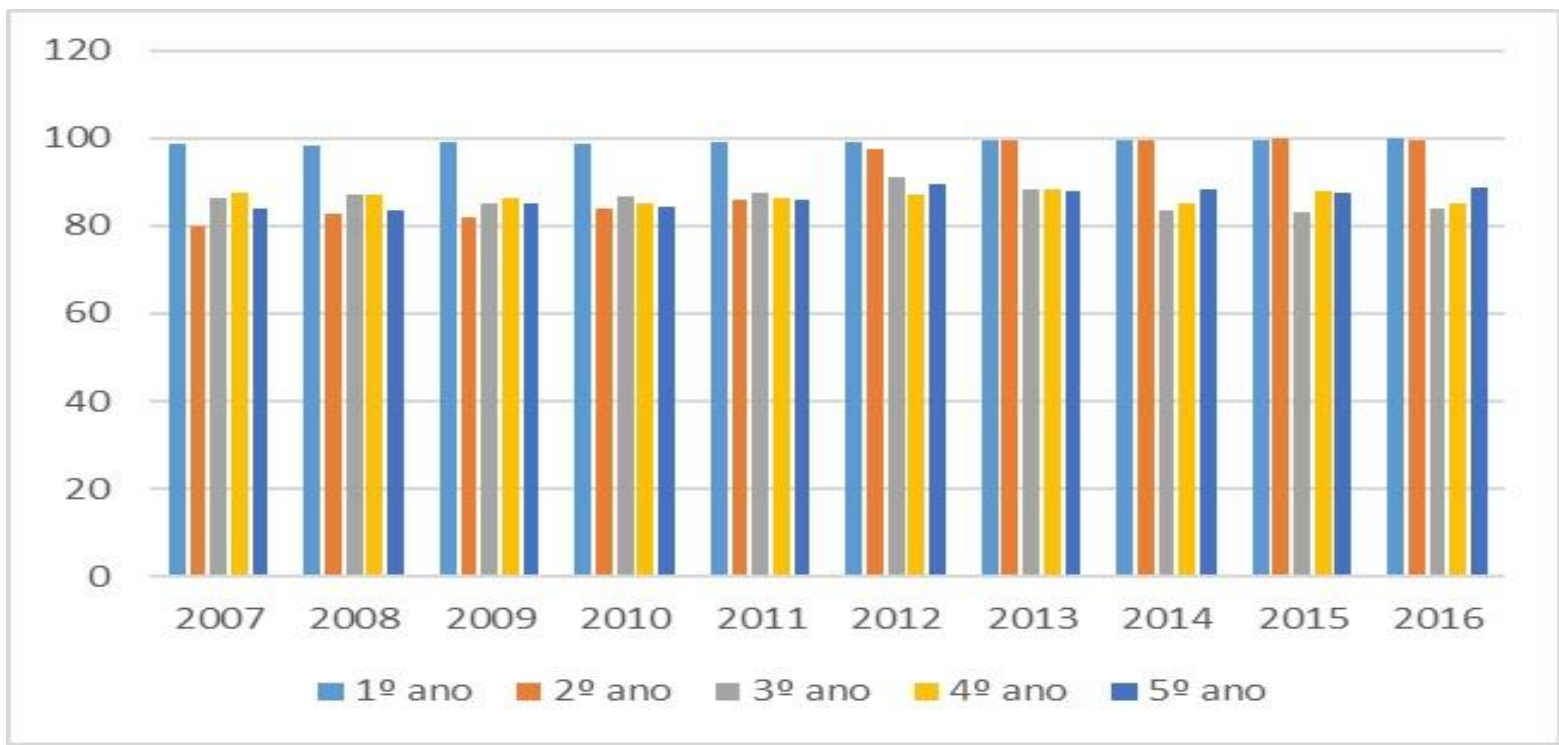

Fonte: Braun (2019, p. 37) 
Conforme apresenta o gráfico, podemos perceber queo percentual de aprovação não varia de forma alarmante nos anos iniciais. Os números mais recentes, especificamente a partir de 2010, indicam um maior equilíbrio nos valores entre o $1^{\circ}$ e 0 $2^{\circ}$, embora o $3^{\circ}$ ano seja 0 ano com o menor índice de aprovação nos últimos três anos, 2014 a 2016. É importante percebermos que de 2007 a 2010 o $2^{\circ}$ ano apresentou a taxa mais baixa de aprovação, superando o $3^{\circ}$ ano. Isso porque a progressão continuada, característica do ciclo de alfabetização, tornou-se obrigatória nas escolas a partir de 2010.

No entanto, os números são mais divergentes no gráfico 2, que apresenta dados sobre a taxa de reprovação nos anos iniciais em Santa Maria. A partir de 2013 os números de reprovação no $1^{\circ}$ e $2^{\circ}$ anos são praticamente nulos, o que condiz com a lei acerca do ciclo de alfabetização que prioriza a não retenção, ou seja, a progressão continuada até o $3^{\circ}$ ano do ensino fundamental. A partir de 2012 pode-se perceber o crescente e elevado índice de reprovação no $3^{\circ}$ ano, superando todos os demais anos que compõem a fase inicial do ensino fundamental, inclusive $02^{\circ}$ ano que, como analisamos no gráfico anterior, possuía a menor taxa de aprovação até 2011.

Gráfico 2 -

Evolução da taxa de reprovação nos anos iniciais do ensino fundamental em Santa Maria, no período de 2007 a 2016.

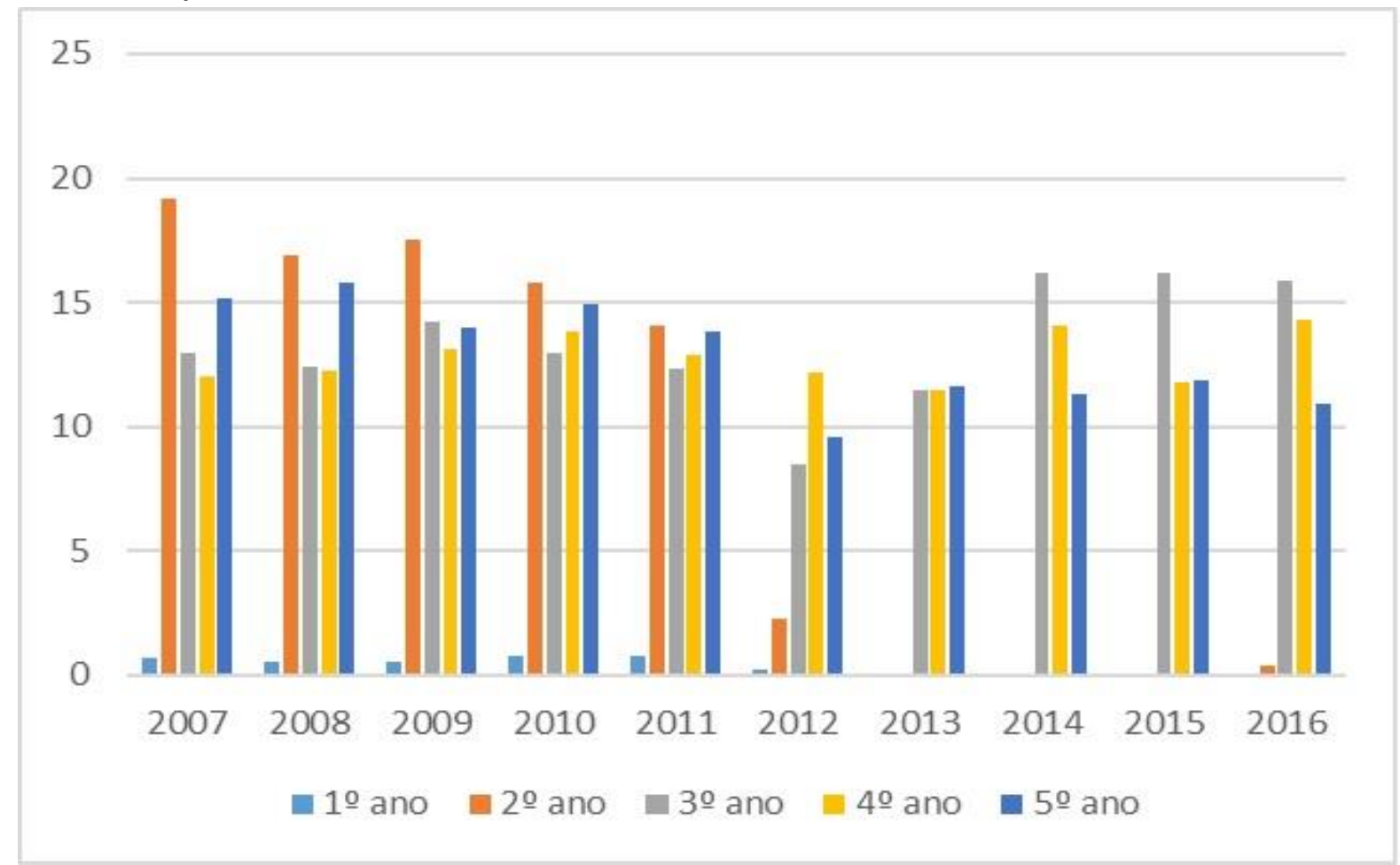

Fonte: Braun (2019, p. 37)

Outra relação que podemos destacar é o alto percentual de reprovação no $5^{\circ}$ ano até 2012, quando o índice cai, embora pouco, e também se eleva a reprovação no $4^{\circ}$ ano. Ou seja, é possível percebermos que enquanto o índice de reprovação no $3^{\circ}$ ano aumenta, o mesmo diminui no $4^{\circ}$ e no $5^{\circ}$ ano. Isso se torna um dado relevante para 
pensar a gestão pedagógica, tendo em vista que o $3^{\circ}$ ano faz parte de um ciclo no qual se tem a ideia de trabalho colaborativo e compartilhado a fim de possibilitar uma aprendizagem sistemática e continuada.

Além disso podemos pensar o alto percentual de reprovação no $3^{\circ}$ ano como uma retenção postergada, pois inicialmente esse índice estava voltado para o $2^{\circ}$ ano. Ou seja, a necessidade de retenção não foi levada em consideração como um fato a ser pensado e excluído das práticas escolares, mas adiado para o último ano do bloco pedagógico, tendo em vista que a lei que põe em prática o ciclo de alfabetização apresenta em seus artigos a não possibilidade de retenção até o $3^{\circ}$ ano.

A partir disso tivemos subsídios para conversar com as professoras acerca da gestão pedagógica nos processos de escolarização, quando encontramos recorrências que perpassam diferentes concepções que se entrelaçam com os dados apresentados anteriormente.

Pensar em currículo, práticas, metodologias, formação continuada, uso de diferentes recursos, como a tecnologia, demanda uma organização sistemática para que tudo aconteça de maneira legal, prática e rica de possibilidades para o trabalho docente e 0 desenvolvimento infantil. Portanto, é necessário que se entenda o papel da gestão pedagógica, entrelaçada a gestão nas mais diferentes esferas, para reconhecer a sua relevância nos processos de ensinar e de aprender. Isso porque

a gestão pedagógica é, de todas as dimensões da gestão escolar, a mais importante, pois está mais diretamente envolvida com o foco da escola que é o de promover aprendizagem e formação dos alunos[...] Constitui-se como a dimensão para a qual todas as demais convergem, uma vez que esta se refere ao foco principal do ensino que é a atuação sistemática e intencional de promover a formação e a aprendizagem dos alunos, como condição para que desenvolvam as competências sociais e pessoais necessárias para sua inserção proveitosa na sociedade e no mundo do trabalho, numa relação de benefício recíproco. Também para que se realizem como seres humanos e tenham qualidade de vida. (Lück, 2009, p. 95)

A gestão pedagógica, dessa forma, leva em conta o modo de organização do professor para o alcance de determinados objetivos, alicerçado na teoria e efetivado na prática, em consonância aos marcos legais federais e municipais. Quando enfocamos no bloco pedagógico ele precisa ser pensado e organizado com o intuito de atender às demandas com o enfoque na alfabetização e na aprendizagem sistemática e continuada proposta pelo Pacto Nacional pela Alfabetização na Idade Certa e pelas diretrizes curriculares nacionais.

Assim, a gestão pedagógica requer um trabalho conjunto e colaborativo, compartilhado entre os alfabetizadores professores do $1^{\circ}$ ao $3^{\circ}$ ano, visando a adequarem-se a essa reformulação a partir do ensino fundamental de 9 anos, levando em consideração as especificidades do trabalho com a criança que agora chega aos seis anos de idade nos anos iniciais e que possui conhecimentos e aprendizagens prévias. Isto é, um capital cultural que influencia no processo de construção do ler e do escrever. 
Dessa forma, para que o trabalho colaborativo de fato aconteça, existem instrumentos e meios que auxiliam nesse movimento. Um deles é o planejamento, elemento chave do processo porque "planejar constitui-se em um processo imprescindível em todos os setores da atividade educacional" (Lück, 2009, p. 32). Assim, tanto no âmbito administrativo, quanto no pedagógico, é importante um planejamento para estruturar e desenvolver uma proposta de trabalho, visando contemplar objetivos e finalidades alicerçados em bases teórico-metodológicas.

Isso fica evidente nas narrativas das participantes que reconhecem a necessidade e a importância desse instrumento no trabalho do professor. Na narrativa que segue percebemos que a professora Marte se manifesta no sentido de afirmar que 0 planejamento é uma forma de organização pedagógica para que a proposta do ciclo de alfabetização se efetive: "Eu acho que é justamente nós termos um planejamento, um olhar atento para nos organizarmos para gerir algo" (MARTE, $2^{\circ}$ ano).

Dessa forma, são múltiplas as funções da gestão na escola, nas mais diversas instâncias e que precisam de uma sistematização, uma intencionalidade, um objetivo, um fim pedagógico pensando na especificidade do contexto escolar. Isso tudo visando aprimorar as práticas pedagógicas e, consequentemente, possibilitar um ensino e uma aprendizagem exitosa nas mais diferentes perspectivas, principalmente da leitura e da escrita, porque

sem planejamento, que organize e dê sentido e unidade ao trabalho, as ações tendem a ser improvisadas, aleatórias, espontaneístas, imediatistas e notadamente orientadas pelo ensaio e erro, condições que tantos prejuízos causam à educação. Sem planejar, trabalha-se, mas sem direção clara e sem consistência entre as ações (Lück, 2009, p. 32)

Quando enfocamos no trabalho pedagógico no ciclo de alfabetização, são ainda mais evidentes a importância e a necessidade do planejamento na tentativa de possibilitar um ensino sistematizado que faça as crianças avançarem em suas hipóteses de leitura e de escrita de maneira gradativa, respeitando sempre o tempo e o espaço de cada uma.

Quando questionadas sobre o planejamento, todas as professoras afirmam que possuem um tempo destinado a esse fim. O que ocorre é que elas não se encontram na escola, tendo em vista que cada uma possui um horário diferente e essa atividade não precisa acontecer dentro da instituição:

"Tem um tempo para o planejamento e nós estamos sempre conversando, trocando ideias, trocando informações." (Marte, $2^{\circ}$ ano)

"É, até que nós nem temos tanto, agora. Assim, tem uma vez por mês. Agora, este ano, é uma vez por mês. Ano passado nós fazíamos até fora do horário, finalzinho da tarde, porque nós não temos muito tempo para se encontrar e conversar. Nós conversamos alguma coisa pelo WhatsApp ou é assim, no intervalinho do recreio, mastigando, tomando um café e comentando com as colegas; e nos momentos de reunião." (Júpiter, 3o ano)

"Nós não temos esse tempo na escola. Se eu disser que tem, eu vou estar mentindo. Muitas vezes por WhatsApp, ou às vezes na hora do recreio nós conversamos. Como eu te falei, eu tenho uma boa ligação com a 
professora do pré, então nós trocamos muitas figurinhas. Essa ligação entre nós duas ajuda muito, contribui muito. Tudo que eu preciso, talvez explorar um pouco mais a questão do corpo, a tesoura e deixar para mim um pouco mais a questão das letras, então nós temos essa relação. $A$ professora do $2^{\circ}$ ano é nova, mas também já tivemos uma ponte. A professora do $3^{\circ}$ ano é mais antiga, então nós já temos uma certa conexão. Nós estamos conseguindo fazer um bom trabalho.' (Vênus, 1ํำ ano)

A partir da última narrativa fica evidente a importância de um trabalho conjunto também desde a pré-escola, levando em consideração a criança que chega mais cedo aos anos iniciais. No entanto, as narrativas apontam que isso de fato não acontece. No entanto, as professoras têm o acompanhamento da gestão escolar nas propostas que são realizadas, sendo todas elas de conhecimento da coordenadora pedagógica e da diretora que, constantemente, estão em sala de aula para conversar com as docentes, conhecer um pouco mais sobre as crianças e sobre as atividades e projetos que são pensados.

"Aqui na escola todas elas [professoras] têm o seu horário de planejamento e não, necessariamente, acontece na escola. Então em determinados momentos, em alguma semana, nós chamamos, sim, para conversar com cada professor. Não somente em uma necessidade como, por exemplo, o conselho de classe ou uma reunião com os pais, mas em outras situações também para sentar com aquele professor, para ver como está a evolução de cada criança, ou situações particulares que são necessárias também de se conversar. Então nós temos esse dia que o professor tem fora da sala de aula, em que outros professores assumem, nós temos essa possibilidade de poder marcar com o professor $e$ estabelecer esse diálogo também, de cada turma. Mas em geral os professores têm esse dia para o seu planejamento, então cada um se organiza da sua forma, mas tem esse horário, um dia por semana, cada semana, para organizar o seu planejamento. E aí eu vou continuamente, como eu te disse, entrar em sala de aula, vou conversando, vou questionando sobre as propostas, o que elas têm de ideias. [...] dentro daquilo que o professor tem como metodologia, eu vou acompanhando o que ele tem em mente, quais são as propostas que ele pretende desenvolver e vou acompanhando esse processo. Isso é muito contínuo, é no dia a dia da escola mesmo porque nós não temos reuniões semanais. Isso é algo que eu penso que faz falta, semanais ou quinzenais, um acompanhamento mais periódico para que nós pudéssemos sentar para conversar." (Saturno, coordenação)

Embora o planejamento não aconteça de maneira colaborativa e compartilhada como se espera durante os três primeiros anos do ensino fundamental, as participantes da pesquisa têm clareza sobre o seu papel como docentes, principalmente quando relacionamos a relevância da gestão pedagógica nesse período de escolarização.

Quando apresentados os índices de aprovação e de reprovação nos últimos anos em Santa Maria/RS, as professoras destacaram que o trabalho docente e compartilhado entre os diversos profissionais da escola é fundamental para qualificar a aprendizagem e, posteriormente, os índices, como podemos reconhecer na narrativa que segue:

"Uma organização no caso escolar, que precisa estar permeada por essa ideia de compartilhamento, do diálogo contínuo, porque a gestão não se 
restringe a uma equipe que vai gerir, que vai coordenar o espaço escolar, mas ela é bem mais ampla. Ela precisa contemplar os professores, os funcionários, a comunidade escolar como um todo: alunos, pais; todos precisam se sentir parte desse processo educativo. Muitas vezes nós vemos nisso algumas coisas que ainda precisamos mudar, em relação mesmo ao olhar dos próprios funcionários quanto a organização de uma sala de aula. Coisas que nós achamos tão simples, em que o professor tem um entendimento de que nós podemos organizar esse espaço de diferentes formas e que muitas vezes entrava num olhar do funcionário, que acha que precisa ser organizado em filas. Estou te dando somente um exemplo de que isso também perpassa esse processo de gestão, de como todos que estão dentro da escola, seja a equipe diretiva, os professores ou os funcionários, precisam ter o entendimento do que é um projeto educativo, de qual é o nosso papel, cada uma dentro das suas responsabilidades, dentro do espaço escolar, de qual é a contribuição dentro desse processo educativo das crianças e, principalmente, os pais. Nós vemos, dentro das propostas dos planos de ação, que isso foi um problema bastante levantado pelas professoras: a não participação dos pais, a omissão de muitas famílias em relação a educação de seus filhos. As demandas têm vindo muito para e escola, desde coisas simples, básicas, que precisariam ser aprendidas em casa e que a escola está, precisa dar conta disso em sala de aula. Então isso sim envolve muito os pais e nós temos trabalho com possibilidades, com estratégias para chamar os pais para as suas responsabilidades com a educação dos filhos." (Saturno, coordenação)

Assim, são várias os elementos que perpassam o processo de ensinar e de aprender, principalmente tendo em vista as modificações e transformações legais que trouxeram outras demandas à escola, ao processo educativo e, consequentemente, ao trabalho do professor.

A professora Marte, embora não tenha desenvolvido um trabalho com turmas de $1^{\circ}$ ano, antes de 2007, manifestou-se na direção de elencar mudanças na gestão pedagógica, mas, principalmente, de pontuar aspectos positivos do bloco pedagógico na vida da criança em processo de alfabetização.

"Eu acho que essa função de tu colocares as crianças mais cedo na escola
veio, em muitos casos, a agregar, porque tem famílias, pode-se dizer
desestruturadas, que não tem muitas condições de dar ajudar as crianças
em casa. Nesse caso, eu acho que a criança mais cedo na escola propicia
um ambiente melhor. Mas para isso, o profissional precisa estar preparado
para ter essa visão de que a criança está precisando, que é acolhedor, de
que ela vai estar melhor na escola. Muitas vezes vai estar melhor na
escola, vai ter chance de melhores aprendizagens do que ficar atirada em
casa só assistindo televisão, ou com o celular na mão, ou com alguma
coisa assim. As crianças hoje, com 4 anos, ficam horas no celular." (Marte,
$2^{\circ}$ ano)

Ou seja, tudo isso envolve o trabalho pedagógico: reconhecer a criança que está se desenvolvendo e aprendendo, pensar em diferentes propostas para englobar os aspectos sociais e emocionais respeitando o tempo e o ritmo individual, a fim de possibilitar práticas exitosas de leitura e de escrita. Nesse sentido, foram várias as propostas destacadas pelas professoras, para auxiliarem a diminuir os índices de reprovação. 
A professora Júpiter, do $3^{\circ}$ ano, destacou propostas de trabalho para contribuir na redução das taxas e a necessidade do trabalho compartilhado como forma de auxiliar na aprendizagem, priorizando a interação grupal, isto é, o trabalho em grupo:

\begin{abstract}
"Aquelas crianças que são mais independentes, eu procuro sentar aquele muito bom com alguém que tem mais dificuldades para dar um apoio. Então é isso que eu procuro fazer em sala de aula, quem sabe mais, ajuda. Claro que eu tenho que cuidar que às vezes aquele que sabe mais quer fazer por aquele que sabe menos [...] tem todo esse tipo de coisa." (Júpiter, $3^{\circ}$ ano)
\end{abstract}

Pensar em propostas que façam as crianças compartilharem hipóteses e construírem coletivamente é essencial para desafiá-las em suas proposições a partir da intervenção e das ideias dos colegas. "Nesse sentido, a criação de espaços de interação entre pares possibilita a construção de desafios capazes de aproximar os aprendizes de análises e sínteses, indispensáveis para a apropriação da língua escrita" (Bolzan; Santos; Powaczuk, 2013, p. 107).

A professora Marte também se manifestou sobre os trabalhos em grupos, dizendo que auxiliam na aprendizagem:

"Nós estamos trabalhando com projetos de leitura. Hoje mesmo era o dia. Toda segunda-feira eu trago uma atividade diferente. Hoje eu fiz uma atividade deles falarem no microfone, lerem as histórias. Tu só pedir para o aluno ler já não é atrativo, então tu colocas alguma coisa diferente. Eu já fiz leitura com roupas, uma fantasia diferente, e interpreta, faz um teatro e em grupo! Sempre em grupo, porque como eu tenho alguns que ainda não leem, eles acabam sendo ajudados pelos colegas." (Marte, $2^{\circ}$ ano)

Assim, algumas professoras apontam propostas de trabalho que podem auxiliar na aprendizagem das crianças ao longo do bloco pedagógico por meio do trabalho grupal, com o intuito de que elas se alfabetizem até o final do $3^{\circ}$ ano, embora a escola priorize e tenha como objetivo a alfabetização consolidada até o final do $1^{\circ}$ ano. Dessa forma, a

interação entre pares consiste em uma atividade capaz de favorecer a expressão de ideias e o confronto de pontos de vista. $O$ intercâmbio entre sujeitos possibilita avanços na construção de conceitos, por meio de auto regulação, a fim de reorganizar seus esquemas intelectuais (Isaia, 2008).

Estar em contato e relação com o outro possibilita a troca de conhecimento sobre um tema comum, que pode ser conhecido e estudado a partir de diferentes explorações, com opiniões diversas e, algumas vezes, opostas. No entanto, é preciso que tenhamos clareza que, independente da metodologia utilizada e dos materiais e ferramentas propostos, a aprendizagem somente será positiva no momento em que terá sentido para a criança, porque a "fase inicial de alfabetização leva-nos a colocar em relevo a compreensão de que todo o conhecimento é gerado a partir da significação que o sujeito aprendiz é capaz de atribuir" (Bolzan; Santos; Powaczuk, 2013, p. 101).

Assim, a professora do $1^{\circ}$ ano destacou que é necessário partir das curiosidades das crianças, fazendo com que o sentido e o significado sejam palavras chave no processo de aprendizagem. 
"Eu trabalho com projetos em sala de aula. Parto muito do interesse das crianças. Esses dias elas queriam saber onde o ar estava escondido dentro da árvore, trabalhando o meio ambiente, então eu introduzi só mostrando, não aprofundando a fotossíntese, porque é importante cuidar da árvore. Eu parto muito da curiosidade delas. Elas querem aprender sobre o fundo do mar. Já que eu estou em meio ambiente, vou trabalhar o planeta água, então eu vou entrar dentro dessa questão." (Vênus, 1ำano)

Logo, pensar em sentido e significado para a criança requer voltar o nosso olhar para o brincar, atividade primeira da criança e por meio da qual ela exterioriza seus sentimentos, vontades e necessidades, permitindo o espaço para a infância ser livre e aproveitada. O brincar é natural da criança, impõe "desafios e questões do cotidiano e realidade das crianças, desenvolvendo a imaginação, criatividade e construindo relações consigo, com o outro e com a sociedade em seu termo mais geral” (Braun, 2017, p. 35).

Além disso, "tendo em vista a especificidade da infância, é necessário trazer para as ações pedagógicas do Ciclo de Alfabetização o brincar, tema recorrente nas discussões sobre a escola" (Brasil, 2012b, p. 19). Isso também fica evidente na manifestação da professora do $1^{\circ}$ ano, que além da curiosidade destacou o trabalho com o brincar e com a ludicidade, apontando os jogos como uma importante ferramenta e metodologia utilizada em seus planejamentos e que podem, de maneira divertida, auxiliar na aprendizagem da lectoescrita:

\begin{abstract}
"Metodologia diversificada, trabalho muito fora da sala de aula. Trabalho com música, trabalho com dança, com todas as partes, realmente, e muitos jogos. Faço muitos jogos com elas e não somente jogos prontos, mas que eu também invento. Assim, é bem diversificado para chamar a atenção delas e não muito papel, Jordana, então é mais qualidade do que quantidade." (Vênus, $1^{\circ}$ ano)
\end{abstract}

Pensar na utilização dos jogos em sala de aula é recorrer a uma metodologia lúdica e divertida para a criança, que tem a possibilidade de reinventar e reconstruir hipóteses e de desenvolver o raciocínio por meio da ação mental. Isso partindo de objetivos claros e com finalidades pedagógicas, objetivando consolidar a leitura e a escrita.

Além disso, ainda pensando no trabalho com sentido e significado, a professora do $2^{\circ}$ ano destacou o trabalho com os diferentes recursos disponíveis na escola, como os equipamentos tecnológicos, tendo em vista que são características da sociedade e das quais as crianças têm conhecimento, sendo essa uma forma de trazê-las para aquilo que já sabem e então desencadear novas aprendizagens. Por isso, é fundamental utilizá-los em sala de aula: "Eu tento utilizar todas as ferramentas possíveis do mundo, tudo o que nós temos na escola, porque aqui o espaço é bem organizado, tem materiais: datashow, sala com computadores, rádios, microfones, videoteca. Por isso, nós usamos diferentes materiais" (Marte, $2^{\circ}$ ano).

A partir disso percebemos e reconhecemos que são muitas as estratégias que podem ser utilizadas para auxiliar na construção das hipóteses das crianças para que elas cheguem ao final do $3^{\circ}$ ano alfabetizadas e avancem para 0 4ํano. Para isso é fundamental um trabalho compartilhado entre toda a escola, nas mais variadas esferas da 
gestão, para que favoreça um trabalho conjunto, pensado e executado no coletivo na tentativa de superar um ensino fragmentado e pautado em índices negativos. Assim, essa é uma forma de valorizar as pessoas envolvidas na instituição e entender que suas responsabilidades contribuem significativamente para a organização escolar (Lück, 2008).

Quando questionadas sobre o que seria indispensável na gestão escolar para que a proposta do ciclo se efetive e para os índices de reprovação diminuam, as professoras assinalaram a questão do trabalho conjunto em sala de aula, um auxiliando o outro a pensar em estratégias para superar dificuldades. Por meio das narrativas percebemos, que tudo gira em torno da gestão pedagógica, afirmando a sua centralidade na escola.

"O trabalho conjunto, proporcionar atividades, proporcionar coisas que façam com que as crianças aprendam e deslanchem. Então o trabalho conjunto." (Júpiter, $3^{\circ}$ ano)

"Eu acho que um trabalho conjunto com o professor. O apoio que eles nos dão é fundamental." (Marte, $2^{\circ}$ ano)

"Eu acho que a coordenação tem que saber o que está acontecendo e fazer intervenções. O que eu quero dizer, vamos ver se eu consigo te explicar, Jordana, acho que tem que se meter mesmo. Se a professora não está legal, tu tens que ter essa liberdade de chegar e dizer que precisa mudar. Antigamente eu já presenciei casos em que a direção deixava rolar para não se incomodar, mas eu acho que não, a gestão precisa se incomodar. Se tu estás em um cargo de gestão, o cargo de diretora, vice, coordenadora existe, então tu tens que peitar, não podes ter medo. Tem que dizer para o colega quem sabe repensar o jeito de trabalhar, claro que falando bem, com jeito, mas perceber que tem coisas que não se faz mais. Aqui nós conseguimos fazer um trabalho bem legal." (Vênus, $1^{\circ}$ ano)

"Eu acho que a primeira coisa é esse trabalho conjunto, de termos um diálogo entre os professores no sentido de entender que esse processo é um ciclo, que independente de mudar a lei, se haverá reprovação no $2^{\circ}$ ano ou não, nós precisamos entender esse processo da criança como uma continuidade. Então é importante que os professores tenham esse diálogo e também com a gestão, comigo, nesse contato em sala de aula. Então os professores precisam estar abertos a isso e eu acho que isso nós já temos aqui na escola, nessa realidade, uma caminhada nesse sentido." (Saturno, coordenação)

Para as quatro professoras esse é um eixo fundamental no trabalho pedagógico que perpassa diferentes esferas: efetivação do bloco pedagógico, metodologias diversificadas, superação dos índices de reprovação, atividades diferenciadas. Além do trabalho conjunto entre as professoras dos três primeiros anos e entre professores e equipes de gestão escolar, é fundamental um trabalho conjunto entre as turmas, interligando atividades e propostas de ensino:

"Estratégia de desenvolvimento de projetos dentro da escola, mais coletivos, que levem a esse interesse pela leitura e pela escrita, propostas de construção, de compartilhamento entre as turmas de produções que são realizadas e que as crianças vejam sentido naquele trabalho, de expor a sua produção e poder falar sobre ela e isso ter um sentido para além do espaço da sala de aula, de fazer para o professor, mas mostrar os 
resultados, o processo que foi desenvolvido, é ir além. Então isso nós também estamos em processo de construção de estratégias que possam ser desenvolvidas com o grupo, com a escola como um todo." (Saturno, coordenação)

A partir de tudo isso, conseguimos reconhecer e compreender que são vários elementos que permeiam o espaço educacional e o processo de ensinar e de aprender. Por meio de esferas específicas, a escola caminha entre perspectivas legais e características únicas e singulares para pensar em propostas de trabalho que contemplem as especificidades da infância e as necessidades de cada criança. $O$ trabalho cooperativo, as atividades diversificadas, a tecnologia e os projetos de trabalho foram o destaque nessa questão, apontando para outras e novas formas de gestão, de organização e de metodologias na tentativa de diminuir os números negativos de reprovação, visando sempre trabalhar com sentido e significado.

\section{Considerações finais}

Ser professor é estar em um movimento de construção dos fazeres diariamente, entrelaçando os saberes teóricos com as emergências da sociedade contemporânea. É estar aberto às possibilidades de se reinventar e de pensar diferente a cada aula, com cada criança. E pensar diferente implica diretamente na gestão dos conhecimentos, da sala de aula, das propostas e atividades.

A partir deste artigo, podemos evidenciar que a gestão pedagógica é fundamental no bloco de alfabetização, que compreende o $1^{\circ}$, o $2^{\circ}$ e $03^{\circ}$ ano da fase inicial do Ensino Fundamental. A organização sistematizada e organizada do professor nesse período é de suma relevância para um ensino de qualidade, que permita que a criança avance gradativamente nas suas hipóteses.

Assim, podemos destacar o planejamento compartilhada como elemento central nesse percurso, na perspectiva de uma troca dialógica entre as professoras para que 0 ensino seja ofertado de modo integrado, com sentido e significado para quem aprende. No entanto, evidenciamos que esse movimento se configura como um contexto emergente no bloco de alfabetização, uma vez que a cultura de colaboração ainda é algo que precisa ser consolidado nas escolas para que seja posto em prática de maneira efetiva. Embora a coordenação acompanhe de perto o trabalho que vem sendo desenvolvido, o ato de planejar de maneira intencional e cooperativa não acontece entre as professoras que atuam nas turmas de alfabetização.

No entanto, embora o planejamento conjunto não aconteça, as professoras têm conhecimento sobre os elevados índices de reprovação e que a gestão pedagógica perpassa os fazeres na tentativa de superação das taxas. Isso porque, ao longo do estudo realizado, conseguimos evidenciar diferentes estratégias para o desenvolvimento de um trabalho que envolva as crianças através do brincar, das suas curiosidades, interligando trabalhos em pares com propostas diferenciadas que envolvem a tecnologia e os diversos espaços da instituição.

Portanto, a gestão pedagógica, ou em outras palavras, a organização do trabalho pedagógico é muito importante quando pensamos no bloco de alfabetização. Embora os desafios e os empecilhos façam parte da rotina escolar, pensar no processo de 
alfabetização requer um olhar atento e uma escuta sensível às necessidades dos estudantes, com o intuito de desenvolver um trabalho que entrelace diferentes saberes e fazeres, na perspectiva de qualificação das aprendizagens das crianças.

\section{Referências}

BAUER, Martin W; GASKELL George. Pesquisa qualitativa com texto, imagem e som: um manual prático. Petrópolis: Vozes, 2002.

BOLZAN, Doris Pires Vargas. Formação de professores: compartilhando e reconstruindo conhecimentos. Porto Alegre: Mediação, 2002.

BOLZAN, Doris Pires Vargas. Verbetes. In: MOROSINI, Marília (org.). Enciclopédia de pedagogia universitária. Glossário II, cap. X, 2006.

BOLZAN, Doris Pires Vargas (org.). Leitura e escrita: ensaios sobre alfabetização. Santa Maria: UFSM, 2007.

BOLZAN, Doris Pires Vargas; SANTOS, Eliane Aparecida Galvão dos; POWACZUK, Ana Carla Hollweg. Cultura escrita: aprender a ler e escrever na escola. Educação, Santa Maria, v. 38, n. 1, 2013, p. 97-110.

BRASIL. Lei n. 9.394, de 20 de dezembro de 1996. Estabelece as diretrizes e bases da educação nacional. Brasília: Câmara Federal, 1996.

BRASIL. Pacto nacional pela alfabetização na idade certa: a organização do planejamento e a rotina do ciclo de alfabetização na perspectiva do letramento: ano 2, unidade 2. Brasília: MEC, 2012.

BRASIL. Pacto nacional pela alfabetização na idade certa: a heterogeneidade em sala de aula e a diversificação das atividades: ano 3, unidade 7. Brasília: MEC, 2012b.

Brasil. Pacto nacional pela alfabetização na idade certa: a organização do trabalho escolar e os recursos didáticos na alfabetização. Caderno 4. Brasília: MEC, 2015.

BRAUN, Jordana Rex. Ciclo de alfabetização: elementos que compõem o processo de ensinar e de aprender. Santa Maria: UFSM, 2017. 87f. Monografia (conclusão de curso de licenciatura em Pedagogia). Centro de Educação, Universidade Federal de Santa Maria.

BRAUN, Jordana Rex. O ensino fundamental de nove anos e a gestão pedagógica: reflexões em torno da implementação do bloco de alfabetização. Santa Maria: UFSM, 2019. 152f. Monografia (Especialização em Gestão Educacional). Centro de Educação, Universidade Federal de Santa Maria.

HORN, Claudia Inês et al. Pedagogia do brincar. Porto Alegre: Mediação, 2014.

ISAIA, Tatiane Peixoto. A interação grupal entre pares e a sua repercussão no processo de construção da lecto-escrita. Santa Maria: UFSM, 2008. 207f. Dissertação (Mestrado em Educação). Programa de Pós-Graduação em Educação, Universidade Federal de Santa Maria.

LARROSA, Jorge et al. Déjame que te cuente: ensaios sobre narrativa y educacion. Barcelona: Alertes, 1995.

LÜCK, Heloísa. Gestão Educacional: uma questão paradigmática. Petrópolis: Vozes, 2008.

LÜCK, Heloísa. Dimensões da gestão escolar e suas competências. Curitiba: Positivo, 2009. 
MILLANI, Silvana Martins Freitas; PEREIRA, Vilsiane. Circuito de atividades: contribuições ao processo de construção da lecto-escrita. In: BOLZAN, Doris P. V. Leitura e escrita: ensaios sobre alfabetização. Santa Maria: UFSM, 2007, p. 32-55.

SERRANO, Francisco Perujo. Pesquisar no labirinto: a tese de doutorado, um desafio possível. São Paulo: Parábola, 2011.

VYGOTSKY, Lev Semenovich et al. Linguagem, desenvolvimento e aprendizagem. São Paulo: Ícone/USP, 1988.

Jordana Rex Braun é estudante no Curso de Mestrado em Educação e no curso de licenciatura em Letras Português na UFSM.

Orcid: https://orcid.org/0000-0001-5805-2274.

Endereço: Avenida Rio Branco, 665/701 - 97010-423 - Santa Maria - RS - Brasil.

E-mail: jordanabraun@hotmail.com.

Doris Pires Vargas Bolzan é professora na Universidade Federal de Santa Maria. Orcid: https://orcid.org/0000-0002-1704-008X.

Endereço: Avenida Roraima, 1000 - 97105-900 - Santa Maria - RS - Brasil.

E-mail: dbolzan19@gmail.com.

Recebido em 18 de outubro de 2019.

Aceito em 21 de dezembro de 2019.

(c) (1) 